\title{
The impact of global tuberculosis in Canada: We are our brothers' keepers
}

I t is estimated by the World Health ORganization (WHO) that one third or about 1.7 billion of the world's population is infected by Mycobacterium tuberculosis (1). Of the annual estimated eight million new active tuberculosis cases, 95\% occur in the developing world, and of these only five million receive some form of treatment and fewer than 0.5 million receive supervised curative regimens (2). With this reality and the population dislocations of the past decade, it is no surprise that there is a spillover effect of the global tuberculosis emergency to the developed world (3). Two papers in this issue of the Journal examine the magnitude of the problem and the impact on tuberculosis rates in industrialized nations (Memish et al, pages 239-243; Thomas and Gushulak, pages 246-255). But the underlying question remains, What can and should be done to address the problem?

In developed countries - Canada (4), the United States (5), Europe (6), Australia $(7,8)$ and New Zealand (9) - rates of tuberculosis declined towards elimination until the mid 1980s, when the decline plateaued, and in some regions rates rose amid concern that human immunodeficiency virus (HIV) coinfection and program failures had caused the reversal (10). Coincidentally, migration of populations from developing countries to these low prevalence regions brought the heritage of earlier infection resulting from exposure to endemic disease in the country of origin and the risk of future reactivation.

Enarson et al (11) showed that immigrants in the 1960s brought to Canada rates of tuberculosis that paralleled the rates in their country of origin. Recent reports from developed countries indicate that increasing percentages of new active cases are attributable to recently arrived immigrants, refugees or migrant workers. In 1993, $52.7 \%$ of cases in Canada (4) and $29.6 \%$ of cases in the United States (5) occurred in the foreign-born, up from $36.1 \%$ in 1983 and $20 \%$ in 1986, respectively. In the United Kingdom, tuberculosis notifications in the Indian ethnic population were 27 times higher, and in the Pakistani-born population 57 times higher, than in the British-born (12). In Switzerland, 51\%, the Netherlands, 41\%, Denmark, 38\% (6) and Australia, 70.7\% (7), respectively, of the cases of tuberculosis were found in the foreign-born in the 1990s. Recently arrived (within five years), immigrants to Canada accounted for $42 \%$ of tuberculosis cases in 1992 (13). In Australia, $43 \%$ of the foreign-born cases had arrived within five years (7), and in the United States $20 \%$ occurred within the first year of arrival (5). In spite of an increasing percentage contribution by immigrants to tuberculosis case loads in North America and western Europe, to date there is no evidence that tuberculosis among the foreign-born population significantly affects the indigenous population of a country that is in the elimination phase of tuberculosis (14). Directly examining this question, Menzies' (15) study of Montreal school children showed no difference between the reactor rates in census tracts with large immigrant populations and those with small immigrant populations.

Immigrant applicants are screened for active infectious pulmonary tuberculosis by physical examination and chest $\mathrm{x}$ ray (required after age 10 in Canada and age 15 in the United States) (16). Both countries demand a negative culture and stable chest $\mathrm{x}$-ray or proof of treatment for those with $\mathrm{x}$-ray abnormalities. Entry requirements vary for European countries (14). Upon arrival in Canada, an annual follow-up for three to five years is recommended (17). The United States does not currently have requirements for follow-up (5). Pre-entry screening eliminates the most infectious cases, and careful follow-up in Canada of those with lung scars gives a case yield of approximately $5 \%$ (18).

The risk of immigrant tuberculosis increasing the pool of drug resistant disease is difficult to measure because mycobacterial culture and sensitivity testing are rarely done routinely in developing countries and only occasionally in sample surveys (19). However, evidence from migrant populations suggests that resistance rates are higher in cases from developing countries. Drug resistance has been assessed in western Canada by Long et al (20) and reported to be $7 \%$ overall and $11 \%$ in immigrants. Drug resistance was 9.9 times higher in immigrants compared with native-born Manitobans (21). In Israel, drug resistance was most common in Russian immigrants (37\%) compared with 16\% in Ethiopians and $12 \%$ in others (22). Drug resistance in the United States in the first quarter of 1991 was $20 \%$ in foreign-born and $12 \%$ in indigenous cases (23).

Strategies to minimize the problem of migrant tuberculosis are proposed in this issue of the Journal by Thomas and echo those of Orr and Hershfield (16) and the European Task Force on Tuberculosis in Immigration (14). All agree on the need for pre-entry screening and mandatory surveillance upon arrival. Orr points out the need for better quality control of the screening physicians and laboratories in the country of 
origin and raises concern over the refugee claimants and visitors who are sometimes lost to initial evaluation. The Canadian guidelines for annual three- to five-year follow-up of those placed under surveillance (17) should be stringently followed. Thomas points to the need to increase health care worker awareness of tuberculosis, to identify cases not under surveillance, especially in the 10 major cities in Canada where immigrants settle. Orr recommends that these persons be managed in culturally sensitive ways, with effective communication between immigration personnel and community services. It is particularly important to avoid legislation such as Proposition 187 of California, which proposes to deny nonemergent care to illegal aliens (24), a proposition that would limit foreign-born access to tuberculosis diagnosis and treatment.

The impact of an individual immigrant case of tuberculosis on the health care system is described in this issue by Memish et al: 871 contacts yielded 149 reactors and 11 converters at a program cost of $\$ 22,076.26$. The authors propose an addition to the immigration screening process, which would require tuberculin skin testing of all applicants and prophylaxis for reactors. The cost of such a proposal, it is suggested, should be borne by the applicant in the country of origin. However, the reliability of execution of such a program would remain questionable in countries where tuberculosis treatment is of uncertain quality and prophylaxis seldom practised. Alternatively, United States guidelines recommend screening on arrival of those under 35 years of age (25). This process was carried out in the United States in 1979 (26) in Vietnamese refugees because the initial group had a prevalence of active tuberculosis over $1 \%$. Forty-six thousand were given prophylaxis. Screening provided early identification of unsuspected disease and early linkage to the health care system for immunization and other medical care. Estimated screening costs of us $\$ 285$ included prophylaxis in a study of Denver refugees (27), and costs of us $\$ 2,000$ to $\$ 3,000$ included cultures, $x$-rays and prophylaxis in a Seattle immigrant screening program (28).

The cost of a nonselective program of tuberculin skin testing and prophylaxis of all immigrants to Canada could be estimated by taking the example year quoted by Memish of 1991, when 230,781 immigrants arrived in Canada. Assuming the prevalence of infection in those from endemic areas to be $50 \%$ (27), of the 176,128 immigrants from Africa, the Middle East, Asia and Latin America, 88,064 would have had reactive tuberculin skin tests. Assuming no active disease, and without calculating the cost of $x$-rays and culture, the cost of prophylaxis alone would be us\$285 (27) (CDN\$396) per person or us $\$ 25$ million (CDN\$35 million) in total.

The WHO (2) has estimated the cost of treating an active case of tuberculosis in the developing world at approximately us $\$ 200$ (CDN\$278) under national tuberculosis program conditions, those designed by the International Union Against Tuberculosis and Lung Disease (IUATLD). The us $\$ 1.6$ billion (CDN\$2.2 billion) necessary to treat the world's annual case load of eight million seems insurmountable. If, however, instead of contemplating prophylaxis of all immigrants, we could find $\$ 35$ million annually from Canada and a per capita equivalent from other developed countries facing imported tuberculosis to contribute to tuberculosis control programs in the developing world, we would have a much more significant impact on the global tuberculosis emergency.

In summary, immigrant tuberculosis accounts for an increasing proportion of cases in the industrialized world, but to date shows no significant impact on the rate of tuberculosis in the indigenous population. Pre-immigration screening practices that diagnose and treat infectious cases are effective and must be maintained. Follow-up of inactive cases upon arrival should be mandatory. However, universal tuberculin skin test screening and prophylaxis of all reactors would be a costly program with limited benefit. Instead, a Canadian commitment to renewed involvement in mutual assistance in the developing world for the treatment of tuberculosis under national control programs would have a larger benefit and reestablish Canada as a leader in addressing the global tuberculosis problem.

\section{REFERENCES}

1. Kochi A. The global tuberculosis situation and the new control strategy of the World Health Organization. Tubercle 1991;72:1-6.

2. World Health Organization. Report on the tuberculosis epidemic, 1995: stop TB at the source. Geneva: World Health Organization, 1995.

3. Appleyard RT. International migration. Challenge for the 90's. International Organization for Migration. Geneva: Imprimeri Genevoise SA, 1991.

4. Statistics Canada. Tuberculosis 1993. The Daily 1995;April 12:3-4.

5. McKenna MT, McCray E, Onorato I. The epidemiology of tuberculosis among foreign born persons in the United States, 1986 to 1993. N Engl J Med 1995;332:1071-6.

6. World Health Organization. Tuberculosis: secular trends of tuberculosis in western Europe. Wkly Epidemiol Rec 1993;68:65-72.

7. Hargreaves J. Tuberculosis notifications in Australia, 1993. Commun Dis Intell 1995;19:334-43.

8. Curran M, Dawson D. Tuberculosis in Australia: bacteriologically confirmed cases in drug resistance, 1993. Commun Dis Intell 1995; 18:343-5.

9. Calder L. Control of tuberculosis in New Zealand. Commun Dis NZ 1992;92:77-8.

10. Raviglione MC, Snider DE, Kochi A. Global epidemiology of tuberculosis: morbidity and mortality of a worldwide epidemic. JAMA 1995;273:220-6.

11. Enarson E, Ashley MJ, Grzybowski S. Tuberculosis in immigrants to Canada. A study of present-day patterns in relation to immigration trends and birthplace. Ann Rev Respir Dis 1979;119:11-8.

12. Davies PDO. Tuberculosis in migration: the Mitchell lecture 1994. J R Coll Physicians Lond 1995;29:113-8.

13. Statistics Canada. Tuberculosis Statistics 1992. (Catalogue \#82-220). Ottawa: Statistics Canada, 1994.

14. European Task Force on Tuberculosis and International Migration. Tuberculosis Control in Europe and International Migration 1993. Eur Respir J 1994;7:1545-53.

15. Menzies R. Tuberculin Sensitivity Among School Children in Montreal. Tuberculosis surveillance research unit at the IUATLD, Progress Report 1991, vol 1. The Hague: KNCV, 1991:121-51.

16. Orr PH, Hershfield ES. The epidemiology of tuberculosis in the 
foreign born in Canada and the United States. In: Reichman LB, Hershfield ES, eds. Tuberculosis - A Comprehensive International Approach. New York: Marcel Dekker, 1993:531-50.

17. Health Canada and Canadian Thoracic Society. Tuberculosis Committee. Guidelines for individuals who are placed under surveillance for tuberculosis post-landing in Canada. Can Commun Dis Wkly 1992;18-20:153-5.

18. Orr PH, Manfreda J, Hershfield ES. Tuberculosis surveillance in immigrants to Manitoba. Can Med Assoc J 1990;142:453-8.

19. Nunn $P$, Felten M. Surveillance of resistance to antituberculous drugs in developing countries. Tuber Lung Dis 1994;75:163-7.

20. Long R, Fitzgerald MJ, Fanning A, Cowie R, Hoeppner V. Western Tuberculosis Group. Antituberculous drug resistance in western Canada 1993-94. ATS Seattle. Am J Respir Crit Care Med 1995;151(Part 2):A513.

21. Long R, Manfreda J, Mandella L, Wolfe EJ, Parker S, Hershfield E. Antituberculous drug resistance in Manitoba from 1980-89. Can Med Assoc J 1993;148:1489-95.

22. Lavy A, Mater A. A ten year survey of $M$ tuberculosis isolates in Israel and their drug resistance. Isr J Med Sci 1994;30:805-10.

23. Bloch $A B$, Cauthen GM, Onorato IM, et al. Nationwide survey of drug-resistant tuberculosis in the United States. JAMA 1994;271:665-71

24. Iseman MD, Starke J. Immigrants and tuberculosis control. N Engl J Med 1995;332:1094-5.

25. Advisory Committee for Elimination of Tuberculosis. Tuberculosis among foreign-born persons entering the United States. MMWR 1990:39(RR 18):1-21.

26. Powell KE, Brown ED, Farer LS. Tuberculosis among Indochinese refugees in the United States. JAMA 1983;249:1455-60.

27. Blum RN, Polish LB, Tapy JM, Carlin BJ, Cohn DL. Results of screening for tuberculosis in foreign born persons applying for adjustment of immigration status. Chest 1992;103:1670-4.

28. Nolan CM, Teklu B, Wu R. The use of sputum cultures in the evaluation of immigrants classified as tuberculosis suspects. Am Rev Respir Dis 1989;140:996-1000.

E Anne Fanning MD FRCPC

Director, TB Services

Alberta Health

Edmonton, Alberta 




The Scientific World Journal
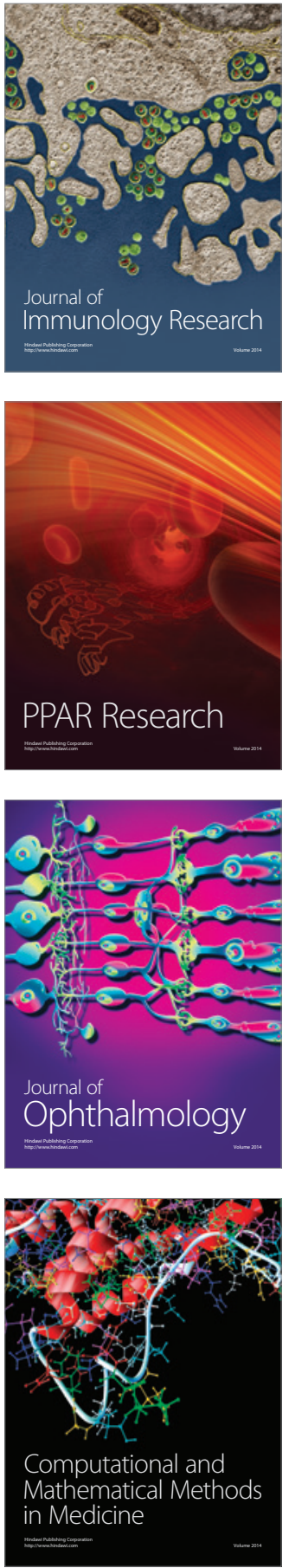

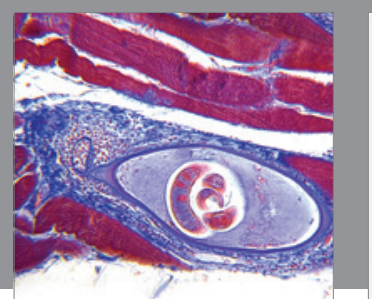

Gastroenterology Research and Practice

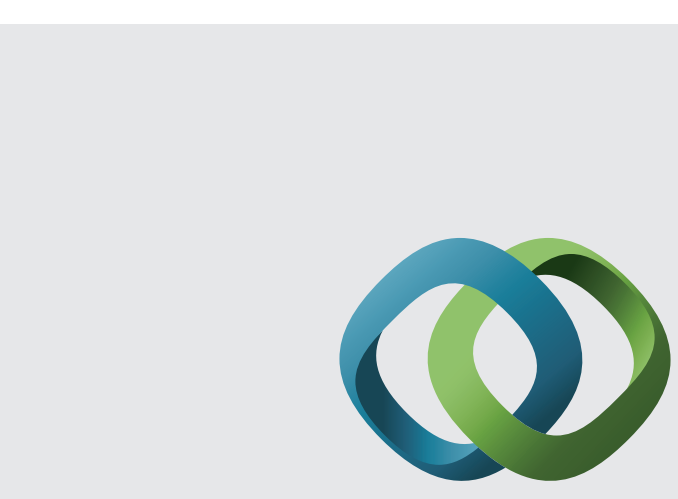

\section{Hindawi}

Submit your manuscripts at

http://www.hindawi.com
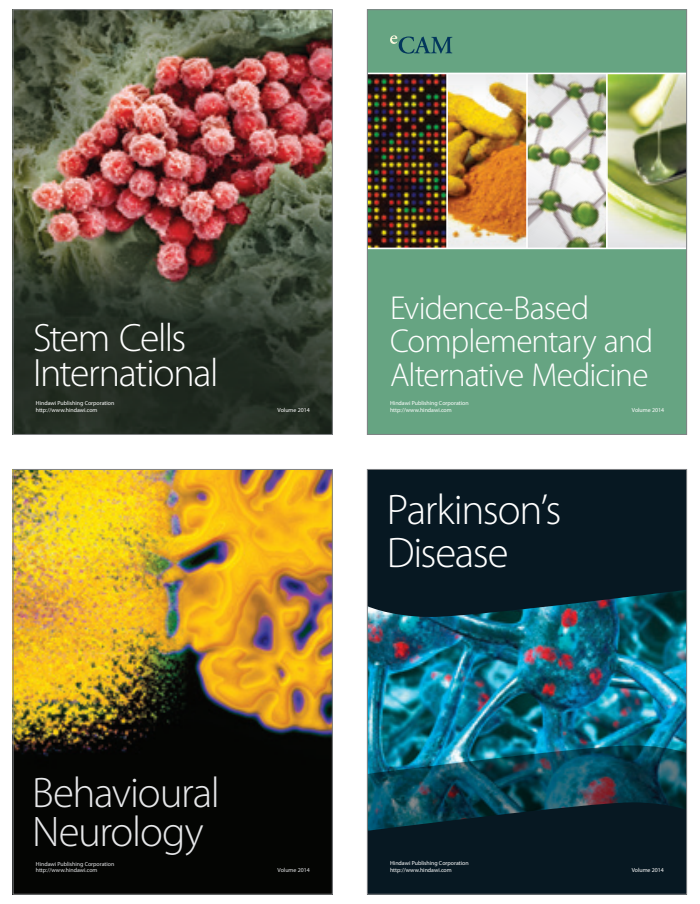


Disease Markers
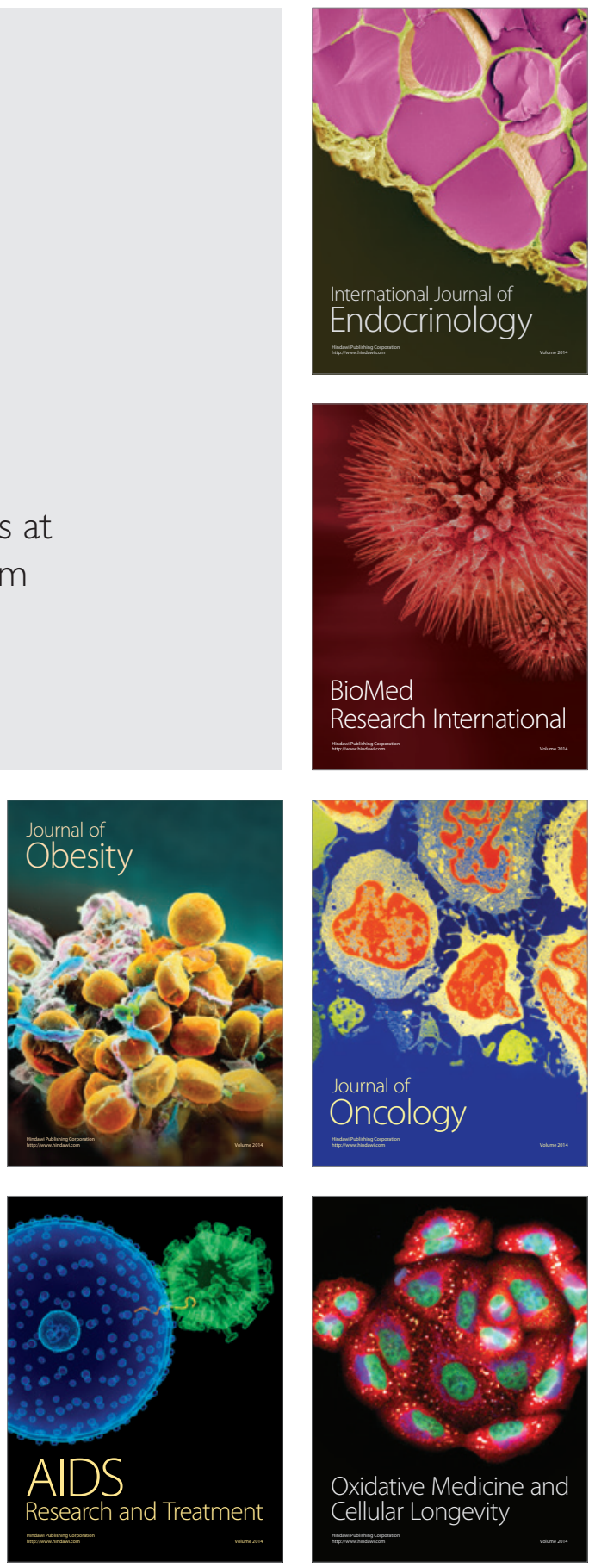